\title{
Analysis of natural and artificial ultramarine blue pigments using laser induced breakdown and pulsed Raman spectroscopy, statistical analysis and light microscopy
}

\author{
I. Osticioli ${ }^{\mathrm{a}, *}$, N.F.C. Mendes ${ }^{\mathrm{a}, \mathrm{b}}$, A. Nevin ${ }^{\mathrm{c}}$, Francisco P.S.C. Gil ${ }^{\mathrm{d}}$, M. Becucci ${ }^{\mathrm{a}, \mathrm{b}}$, E. Castellucci ${ }^{\mathrm{a}, \mathrm{b}}$ \\ a Dipartimento di Chimica, Università di Firenze, Polo Scientifico, Via della Lastruccia 3, 50019 Sesto Fiorentino, Firenze, Italy \\ ${ }^{\mathrm{b}}$ LENS, Università di Firenze, Polo Scientifico, Via N. Carrara 1, 50019 Sesto Fiorentino, Firenze, Italy \\ c Dipartimento di Fisica, Politecnico di Milano, Piazza Leonardo da Vinci 32, Milano, 20133, Italy \\ d Physics Department, University of Coimbra, P-3004 516 Coimbra, Portugal
}

\section{A R T I C L E I N F O}

\section{Article history:}

Received 22 June 2008

Received in revised form

16 November 2008

Accepted 23 November 2008

\section{Keywords:}

Time-resolved Raman spectroscopy

Laser induced breakdown spectroscopy

Lapis lazuli

Lazurite

Artificial ultramarine

Principal component analysis (PCA)

\begin{abstract}
A B S T R A C T
Pulsed laser induced breakdown spectroscopy (LIBS) and Raman spectroscopy were performed using a novel laboratory setup employing the same Nd:YAG laser emission at $532 \mathrm{~nm}$ for the analysis of five commercially available pigments collectively known as "ultramarine blue", a sodium silicate material of either mineral origin or an artificially produced glass. LIBS and Raman spectroscopy have provided information regarding the elemental and molecular composition of the samples; additionally, an analytical protocol for the differentiation between natural (lapis lazuli) and artificial ultramarine blue pigments is proposed. In particular LIBS analysis has allowed the discrimination between pigments on the basis of peaks ascribed to calcium. The presence of calcite in the natural blue pigments has been confirmed following Raman spectroscopy in specific areas of the samples, and micro-Raman and optical microscopy have further corroborated the presence of calcite inclusions in the samples of natural origin. Finally multivariate analysis of Laser induced breakdown spectra using principal component analysis (PCA) further enhanced the differentiation between natural and artificial ultramarine blue pigments.
\end{abstract}

(C) 2008 Elsevier B.V. All rights reserved.

\section{Introduction}

Ultramarine was originally used to distinguish the blue pigment lapis lazuli (extracted from the mineral lazurite (approximate formula $\left.(\mathrm{Na}, \mathrm{Ca})_{8}\left(\mathrm{AlSiO}_{4}\right)_{6}\left(\mathrm{SO}_{4}, \mathrm{~S}, \mathrm{Cl}\right)_{2}\right)$ and imported from Asia) from other less expensive blue pigments, in particular the blue copper mineral pigment azurite $\left(\mathrm{Cu}_{3}\left(\mathrm{CO}_{3}\right)_{2}(\mathrm{OH})_{2}\right)$ [1]. In the past the principal source of the mineral and pigment was in ancient quarries of Badakshan (now Afghanistan). Another large deposit of lazurite is located in the Andes Mountains in the area of Ovalle in Chile where the pre-Columbian cultures (including the Incas) mined lapis lazuli as a semi-precious stone. The natural pigment lapis lazuli [from the Latin lapis (stone) and lazulus (blue)] contains grains of the cubic mineral lazurite which accounts for the typical vibrant and deep blue colour of the ground mineral pigment. As a mineral deposit, lazurite is commonly associated with other silicate minerals such as diopside $\left(\mathrm{CaMgSi}_{2} \mathrm{O}_{6}\right)$, forsterite $\left(\mathrm{Mg}_{2} \mathrm{SiO}_{4}\right)$, wollastonite $\left(\mathrm{CaSiO}_{3}\right)$ together with calcite $\left(\mathrm{CaCO}_{3}\right)$ and pyrite $\left(\mathrm{FeS}_{2}\right)$.

The pigment ultramarine, extensively used in Europe throughout the 14 th and 15 th centuries, is obtained by crushing, grinding

\footnotetext{
* Corresponding author.

E-mail address: iacopo.osticioli@unifi.it (I. Osticioli).
}

and cleaning the raw material to separate the other minerals from lazurite, as described in artists' accounts [2]. Later, the use of lapis lazuli was limited due to its high price and the widespread availability of cheaper alternatives (including Prussian Blue $\mathrm{Fe}_{7}(\mathrm{CN})_{18}\left(\mathrm{H}_{2} \mathrm{O}\right)_{x}$ and the potassium-cobalt glass pigment Smalt). However, in 1828, an artificial ultramarine was synthesized by Jean Baptiste Guimet and was subsequently adopted by European artists. Similar in chemical composition to lazurite, synthetic ultramarine has an approximate formula $\mathrm{Na}_{6-10} \mathrm{Al}_{6} \mathrm{Si}_{6} \mathrm{O}_{24} \mathrm{~S}_{2-4}$ which can vary with the manufacturing conditions, namely with the purity and the different proportion of the ingredients.

The identification and discrimination between natural (hence forth refereed to as lapis lazuli) and the synthetic ultramarine is relevant to the analysis of works of art, providing information regarding both the technique used by artists during execution and the historical practice. As an example, the use of artificial ultramarine in Impressionist and post-Impressionist paintings is common [1] whereas the presence of such a pigment in a 14th century painting could be ascribed to subsequent interventions of restoration. Since lapis lazuli and artificial ultramarine have similar chemical composition and properties, their discrimination is not straightforward, and usually necessitates invasive analysis. Generally lapis lazuli can be recognized with optical microscopy or under high-magnification scanning electron microscopy (SEM), the mor- 
phology of the pigment particles and variation in the particle size distribution of lapis lazuli are distinctly different from the uniform, small and round particles of the synthetic ultramarine blue pigment [3]. Furthermore, spectroscopic techniques have been used for the identification of natural lapis lazuli and synthetic ultramarine; Fourier transform infrared spectroscopy (FTIR) has been proposed for the differentiation between the two, with the spectra of lapis lazuli associated with selected vibrational bands ascribed calcite and wheddelite [calcium oxalate $\left(\mathrm{Ca}\left(\mathrm{CO}_{2}\right)_{2} \cdot \mathrm{H}_{2} \mathrm{O}\right)$ ], confirmed using energy dispersive X-ray (EDX) analysis which revealed the presence of calcium within particles in the pigment mixture [4]. In this case, the presence of calcium associated with lazurite but rather from the presence of natural impurities (including calcite) within the pigment mixture. On the other hand, in the case of artificial ultramarine, no calcium is present since the essential elements for its synthesis are sodium (Na), aluminium $(\mathrm{Al})$, sulfur $(\mathrm{S})$ and silicon (as $\mathrm{SiO}_{2}$ ).

Micro-FTIR spectra of lapis lazuli from Afghanistan have also been reported and show a narrow band at $2340 \mathrm{~cm}^{-1}$ absent from the spectra of the synthetic pigments, but this band has not been assigned [5]. The application of micro-FTIR and SEM-EDX spectroscopy for the discrimination of ultramarine pigments is invasive and requires sample preparation.

Alternative and complementary analysis of ultramarine is provided by Raman [6] and laser induced breakdown spectroscopy (LIBS) [7], and the integration of the two techniques is the focus of this work.

Raman spectroscopy has often been used for the molecular analysis and the characterization of inorganic pigments from works of art $[8,9]$, with a variety of databases available for ancient and modern pigments [10-12]. A wide range of artistic and historical materials have been studied by using this non-destructive, and in some cases non-invasive [13,14], spectroscopic technique. The coupling of Raman spectroscopy to LIBS is particularly advantageous, as both molecular and elemental information can be obtained. Indeed, advantages from combining the techniques have been described elsewhere [15-17] where analyses based on Raman spectroscopy and LIBS have been undertaken in order to identify pigments in 19th century icons and polychromy. In these cases, measurements were carried out using two distinct instrumental devices employing two different laser sources. The novelty introduced by the present work is that the same laser was employed for both Raman and LIBS measurements.

Analysis of laser induced breakdown emissions, which arise from the formation of a hot plasma during ablation, provides many advantages for elemental analysis of art, as described recently [18-20]. LIBS can provide qualitative and, at times, quantitative [21] information about the elemental composition of an object. The response time of analysis is on the order of only a few seconds and no sample preparation or prior treatment is required. When manual sampling is compromised due to the hardness or brittleness of a work of art, as in the case of ceramics, bronzes or stone, LIBS is particularly powerful since sampling and analysis occur simultaneously. With the use of microscope objectives coupled with LIBS, craters (and sampling) on the order of $10 \mu \mathrm{m}$ can be achieved, making analysis effectively micro-destructive and invisible to the naked eye [22]. In addition, as many works of art cannot be moved, the possibility of performing analysis in museums and archeological sites makes LIBS particularly important.

As part of this work, a prototype instrument capable of carrying out Raman and LIBS by using a single pulsed laser source was developed for the analysis of pigments. For this study, six different samples were considered; three commercially available artificial ultramarine pigments; two different samples of natural pigments, one from Afghanistan and the other from Chile; and a lapis lazuli stone deposit. All samples were analysed using both Raman spec- troscopy and LIBS. In addition, in order to identify changes or differences in spectra in a large data set, principal component analysis (PCA) was employed for the analysis of Laser induced breakdown spectra. PCA is a multivariate method which can be used to describe the variance-covariance structure of a set of data by using a linear combination of original variables to form principal components (PCs). Combinations of the original dimensions describe the largest variance between data sets, and most of the information from the original data set can be accounted for by a smaller number of variables. The use of multivariate statistical methods, including PCA, for the differentiation between similar laser induced breakdown spectra has been particularly useful for the separation of different samples of Roman ceramics known as "Terra Sigilata" [23,24]. A similar approach for the analysis of spectra recorded from pigment samples in the region between 390 and $399 \mathrm{~nm}$ has been explored.

\section{Experimental}

\subsection{Samples}

Five different ultramarine blue pigments were purchased from specialized suppliers. Three of the pigments are synthetic and were supplied by the Italian firms Phase (label ART01), C.T.S. (label ART02) and Zecchi (label ART03). The two natural lapis lazuli pigments were both supplied by Zecchi and are from Chile (label NAT04) and Afghanistan (label NAT05). All the synthetic and natural pigments were supplied as powders. In addition, a stone sample containing lazurite and other minerals (label MIN06) has been studied together with the pigments. For reference, all powdered samples were examined using polarised light microscopy in transmission at $400 \times$ magnification in plane polarised light and with crossed-polars; micro-Raman spectroscopy was also carried out on the powdered samples. For the LIBS and Raman analysis the powders were pressed in tablets and analysed. No further treatment has been performed on the mineral sample.

\subsection{Raman-LIBS setup}

For pulsed Raman and LIBS measurements, the second harmonic emission $(532 \mathrm{~nm})$ of a nanosecond Q-switched Nd:YAG laser (8 ns, $20 \mathrm{~Hz}, 0.01-115 \mathrm{~mJ} \mathrm{pulse}^{-1}$ ) was used as irradiation source [25]. The instrument allows time-resolved acquisition which has been used mainly to discriminate Raman signal from background radiation or luminescence contributions (which is of particular interest for measurements in the outdoors), and to acquire laser induced breakdown spectra with a suitable delay and gate time. A general scheme of the instrumentation is shown in Fig. 1.

In Raman and LIBS the emitted light is collected from the sample through the same lens used to focus the laser beam, and collected light is subsequently focused into a $0.30 \mathrm{~m}$ imaging spectrograph equipped with three interchangeable diffraction gratings with 150 , 300 and 1200 grooves $\mathrm{mm}^{-1}$. A notch filter, the position of which has been carefully optimized in order to obtain the clearest Raman signal, was mounted on a stage that can be easily removed in order to perform LIBS measurements. The ICCD is a $1024 \times 256$ imaging pixel detector with a minimum gate speed of $1 \mathrm{~ns}$. Energy values measured before the focusing lens were $75 \mathrm{~W} \mathrm{~cm}^{-2}$ per pulse for Raman measurements and $1875 \mathrm{~W} \mathrm{~cm}^{-2}$ for LIBS, with a gate width of $700 \mathrm{~ns}$ and a gate delay of $200 \mathrm{~ns}$. The diameter of the area analysed was on the order of $50 \mu \mathrm{m}$ for both Raman and LIBS.

\subsection{Polarized light microscope}

The microscope used is a Leica DM microscope with a Nikon Coolpix digital camera attached. Transmission was obtained with Tungsten illumination and white balance applied to images. 


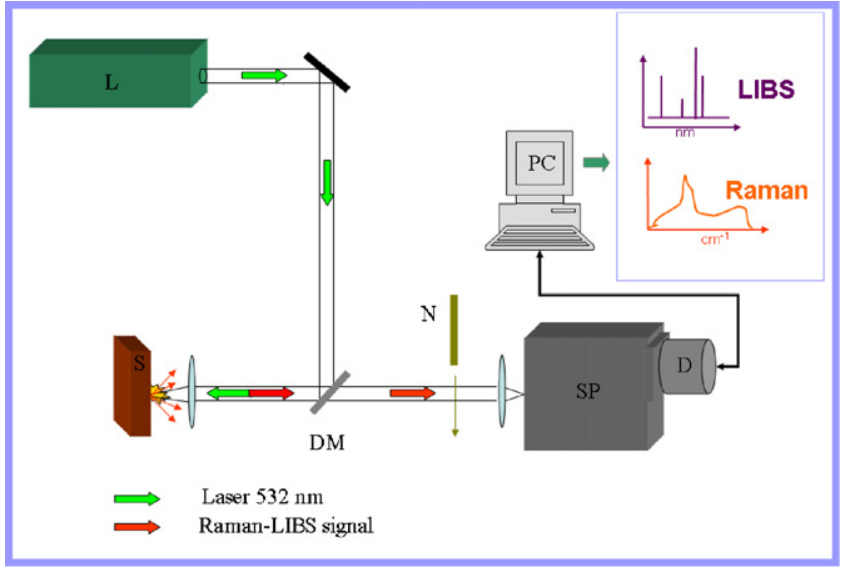

Fig. 1. General scheme of the instrumentation used to perform pulsed Raman and LIBS analysis: L, laser; M, mirror; S, sample; DM, dichroic mirror; N, notch filter; SP, spectrometer; D, detector.

Dispersions were examined and photographed at $400 \times$ magnification.

\subsection{Micro-Raman}

For micro-Raman analysis, a Renishaw RM 2000 single grating ( 1200 grooves $\mathrm{mm}^{-1}$ ) spectrometer coupled to an Argon ion laser source $(514.5 \mathrm{~nm}$ ) equipped with a $50 \times$ objective for analysis was used. The spectral resolution was approximately $4 \mathrm{~cm}^{-1}$, and instrumental calibration was carried out using the Raman peak at $520 \mathrm{~cm}^{-1}$ of silicon. Acquisition times were on the order of $30 \mathrm{~min}$, depending on signal intensity, and the power at the surface of the sample was in the range of $4-40 \mathrm{~mW} \mathrm{~cm}^{-2}$. The diameter of the area analysed was on the order of $5 \mu \mathrm{m}$.

\section{Results and discussion}

\subsection{Pulsed Raman and LIBS}

Fig. 2 shows the pulsed Raman spectra acquired with the laser emitting at $532 \mathrm{~nm}$. The use of a pulsed source coupled with

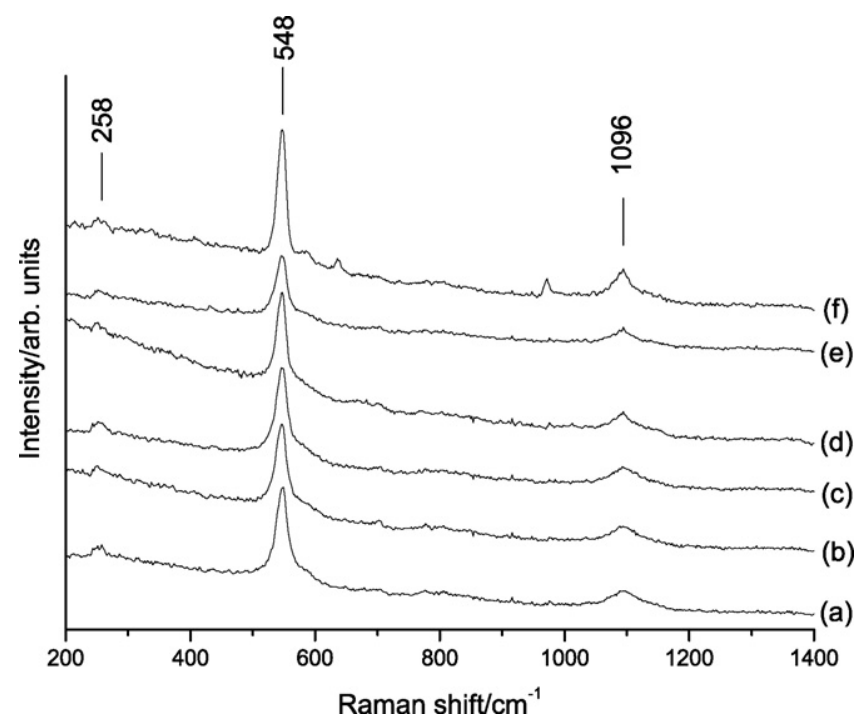

Fig. 2. Pulsed Raman spectra of different ultramarine blue samples: (a) ART01; (b) ART02; (c) ART03; (d) NAT04; (e) NAT05; (f) MIN06. Spectra were acquired with laboratory lighting (i.e. not in darkness). an intensified and gated detector allowed the full removal of the environmental light by applying a gate time of $100 \mathrm{~ns}$ and a delay time of $12 \mathrm{~ns}$ and acquisition was approximately $30 \mathrm{~min}$. Although with the analysis of certain pigments, including Lead White $\left(2 \mathrm{PbCO}_{3} \mathrm{~Pb}(\mathrm{OH})_{2}\right)$ or Cinnabar $(\mathrm{HgS})$, which may oxidise with laser irradiation at higher fluences, no damage to the area analysed was observed in the analysis of samples in this work. The absence of any alteration and discolouration of the blue pigment crystals were also monitored using optical microscopy.

The symmetric stretching vibration $\left(v_{1}\right)$ of $\mathrm{S}_{3}{ }^{-}$at $548 \mathrm{~cm}^{-1}$ is clearly appreciable in all spectra of lapis lazuli and artificial ultramarine In addition, the bending vibration $\left(v_{2}\right)$ of $\mathrm{S}_{3}{ }^{-}$at $258 \mathrm{~cm}^{-1}$ and the first overtone of the stretching vibration $\left(1 v_{1}\right)$ at $1096 \mathrm{~cm}^{-1}$ are also visible [6]. The spectrum of the stone sample (MIN06) is of particular interest since it indicates the presence of wollastonite $\left(\mathrm{CaSiO}_{3}\right)$, a mineral commonly associated with lapis lazuli and absent in the purified pigments; its Raman bands are visible at $637 \mathrm{~cm}^{-1}$ corresponding to the $\mathrm{Si}-\mathrm{O}-\mathrm{Si}$ bending and at $970 \mathrm{~cm}^{-1}$ due to the $\mathrm{Si}-\mathrm{O}$ stretching [26,27].

It is clear from Fig. 2 that Raman spectra of the samples considered are not sufficiently different from one another to permit the discrimination between lapis lazuli and artificial ultramarine pigments. Samples appear of similar chemical composition and molecular conformation, and the spot size of analysis effectively averages molecular variations within the area of analysis of samples.

LIBS was performed on the same samples in order to determine their elemental composition. Fig. 3 shows Laser induced breakdown spectra acquired in a spectral range between 305 and $340 \mathrm{~nm}$. The atomic emissions of aluminium (Al) at 308.2 and $309.3 \mathrm{~nm}$ are clearly observable in all the spectra together with the emission of sodium $(\mathrm{Na})$ at $330.2 \mathrm{~nm}$, whereas, the atomic emissions of calcium (Ca) at 315.9 and $318.1 \mathrm{~nm}$ are evident only in the natural ultramarine pigments from Afghanistan and Chile; finally, the spectra

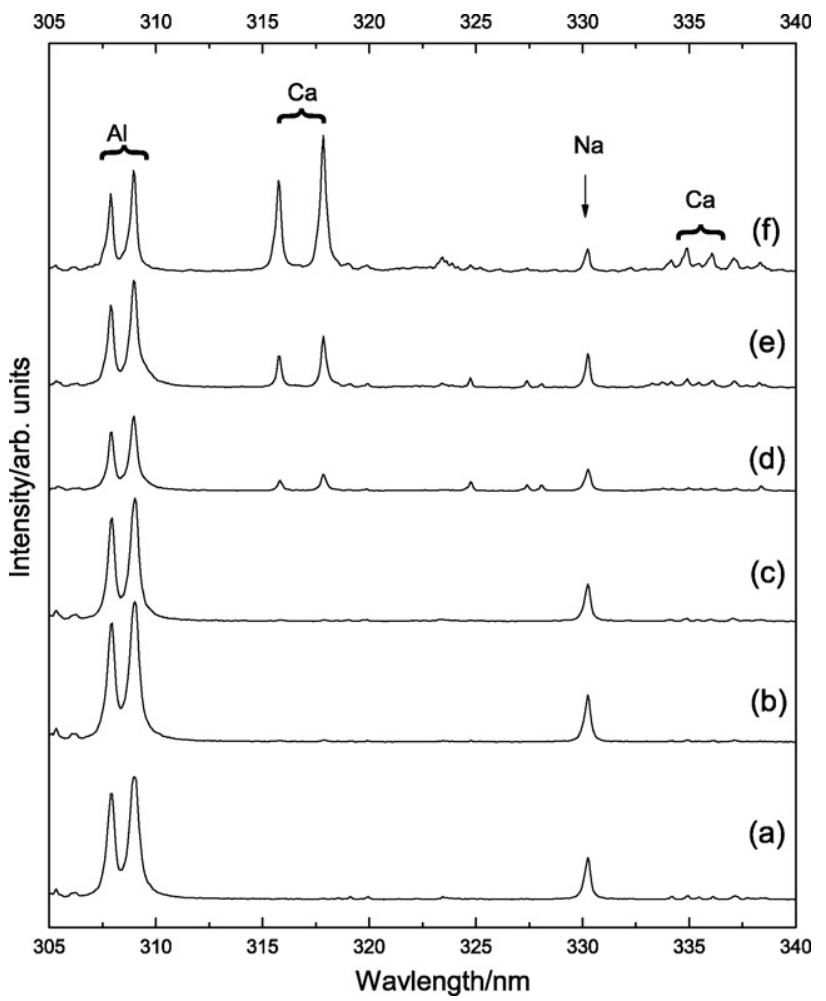

Fig. 3. Laser induced breakdown spectra recorded in the region between 305 and $340 \mathrm{~nm}$ of ultramarine blue samples: (a) ART01; (b) ART02; (c) ART03; (d) NAT04; (e) NAT05; (f) MIN06. In the artificial samples (a)-(c) calcium is completely absent. 


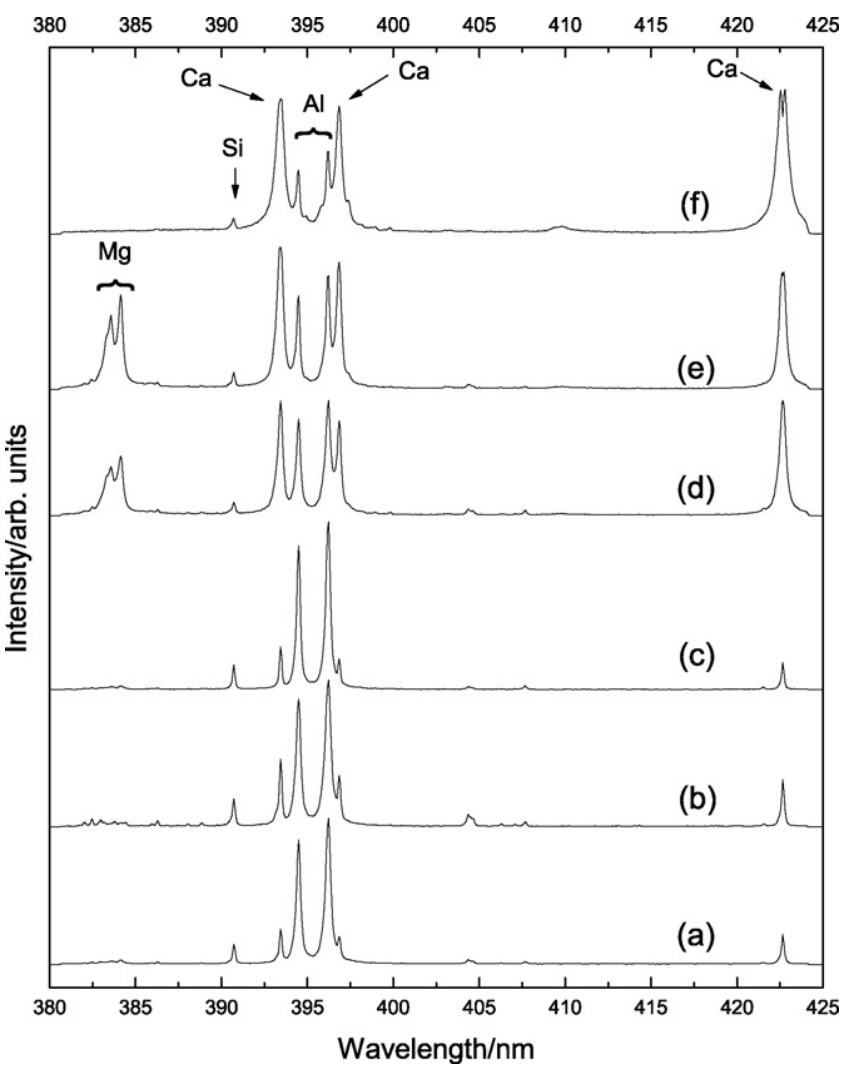

Fig. 4. Laser induced breakdown spectra recorded in the region between 380 and $425 \mathrm{~nm}$ of ultramarine blue samples: (a) ART01; (b) ART02; (c) ART03; (d) NAT04; (e) NAT05; (f) MIN06. In the natural samples (d)-(f) the intensity of calcium emissions are higher than the intensity of aluminium.

of the stone sample shows emission lines of calcium which are more intense than those of aluminium and also weak emissions of calcium at 334.7 and $336.1 \mathrm{~nm}$ are observable. In all samples the presence of calcium in the spectra is ascribed to the presence of both calcite and wollastonite.

Fig. 4 shows laser induced breakdown spectra acquired in a spectral range between 380 and $425 \mathrm{~nm}$. In these spectra the atomic emissions of aluminium ( $\mathrm{Al}$ ) at 394.4 and $396.1 \mathrm{~nm}$ and silicon (Si) at $390.5 \mathrm{~nm}$ are clearly detected. Intense atomic emissions of magnesium $(\mathrm{Mg})$ are observable in the Laser induced breakdown spectra of lapis lazuli from Afghanistan and Chile, probably due to the presence of diopside $\left(\mathrm{CaMgSi}_{2} \mathrm{O}_{6}\right)$ and forsterite $\left(\mathrm{Mg}_{2} \mathrm{SiO}_{4}\right)$. The lack of emission bands from $\mathrm{Mg}$ in the mineral sample spectrum could be due to a weak concentration of magnesium-based minerals in the stone analysed. On the other hand, the presence of magnesium in the natural ultramarine blue pigments from the Andes and Afghanistan, is ascribed to an insufficient purification of the finely ground natural pigments. Calcium (Ca) emissions at 393.4, 396.8 and $422.7 \mathrm{~nm}$ have been found in the spectra of all samples. However, with natural pigments and the stone sample, the intensities of the calcium emissions are greater than those of the aluminium emissions. Furthermore the emission of calcium at $422.7 \mathrm{~nm}$ in the laser induced breakdown spectrum of lapis lazuli shows auto-absorption that could be ascribed to a high concentration of this element in the ground pigment.

\subsection{Principal component analysis (PCA)}

In order to investigate the spectral variation related to the presence and intensity of emissions from calcium, statistical analysis has been carried out using principal component analysis (PCA) on laser induced breakdown spectra. Multivariate analysis of spectra was performed on spectra in the range between 390 and $399 \mathrm{~nm}$. A total of 96 spectra were recorded, at 4 different positions and on 4 different days for each of the 6 samples. Cosmic noise and spikes were removed from spectra, and no corrections (for example manual baseline adjustment) were applied.

Spectra were vector normalized to correct for variations in measurement geometry which may influence the over-all recorded intensity $[28,29]$. Spectra were then compared with PCA using Software for Chemometric Analysis (SCAN), Minitab, to yield principal components for each spectrum and loading plots of each component.

The score plot in Fig. 5(a) shows three clusters of data in a score plot of the first two principal components (PCs), PC1 and PC2, which together account for $98 \%$ of the total spectral variance.

Contributions to the total variance of spectra can be understood with an examination of the loading plot in Fig. 5(b). The loading plot indicates that contributions from the band at approximately 393.5 and $397 \mathrm{~nm}$ of calcium are associated with a negative PC1, hence accounting for the position of natural and mineral samples on the left of the score plot. The emissions at 394.5 and $396 \mathrm{~nm}$ of aluminium account for positive PC1 and PC2. Finally, the silicon emission at $390.5 \mathrm{~nm}$ brings a weaker positive contribution to PC2.

The score plot allows the visualisation of the similarity within the large set of data, as seen in Fig. 5(a). Differences in the laser
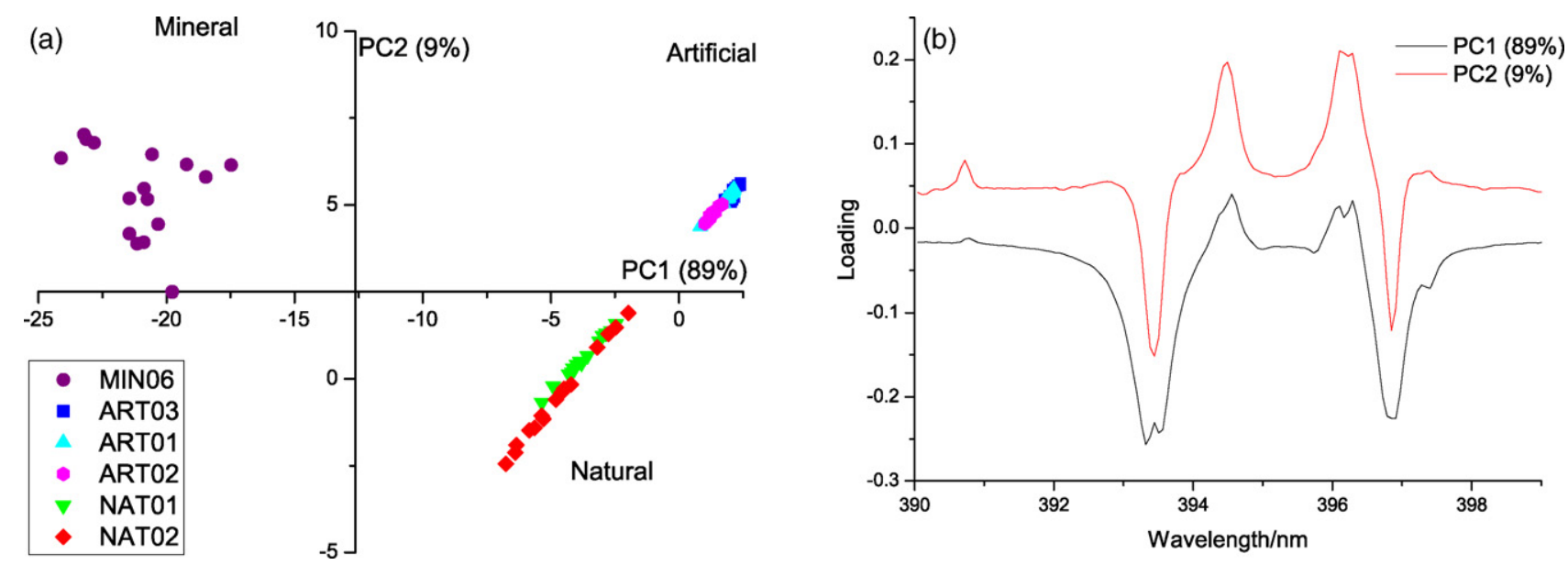

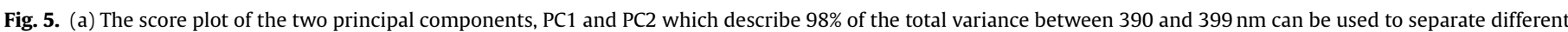

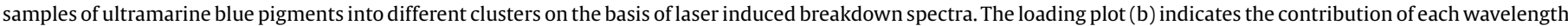
to PC1 and PC2. 


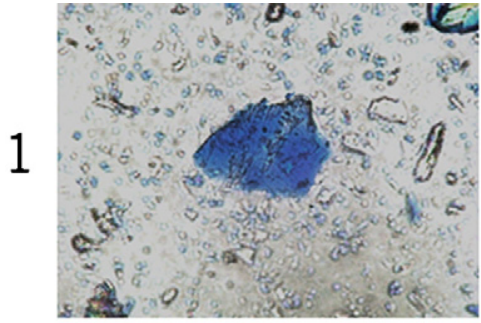

(a)

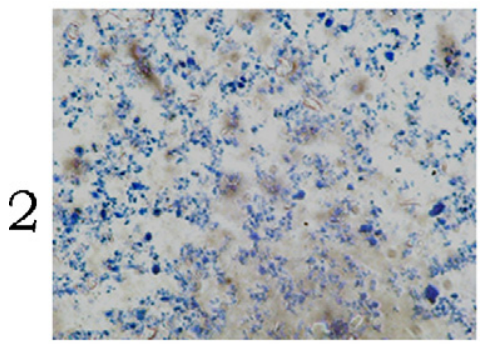

(a)

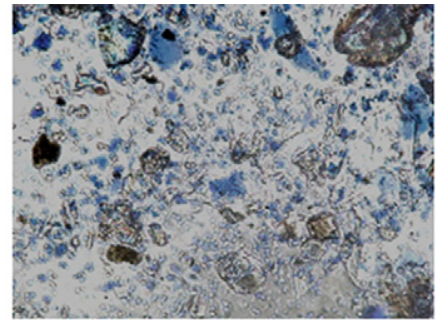

(b)

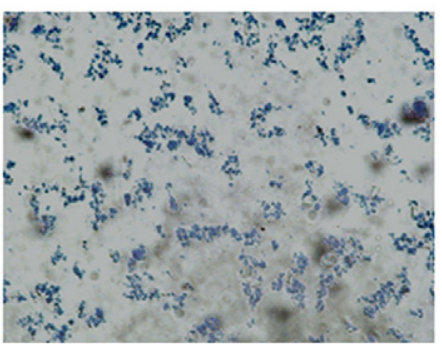

(b)

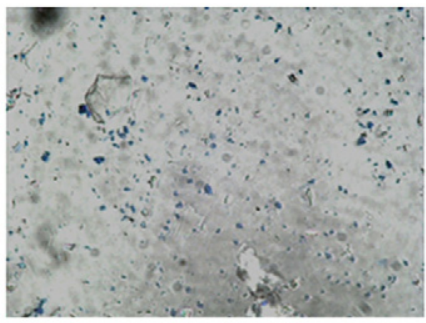

(a)

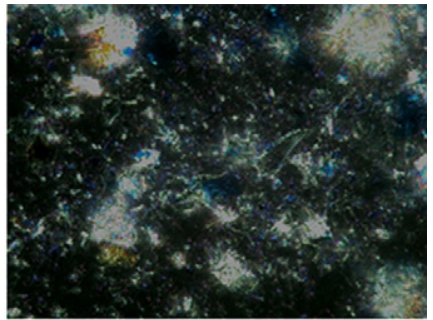

(c)

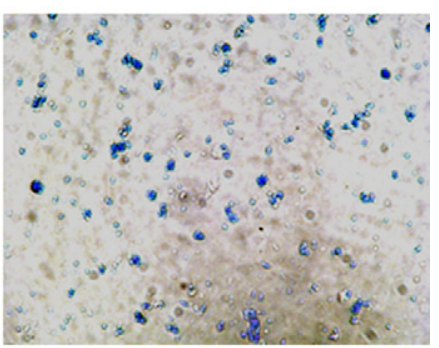

(c)

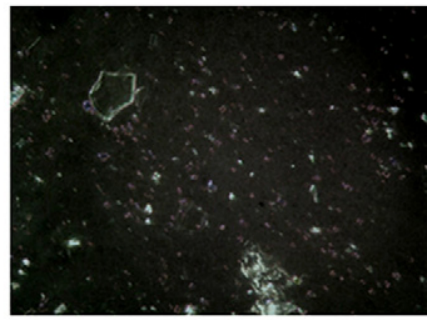

(b)

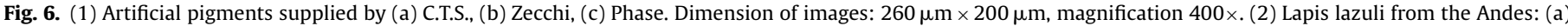

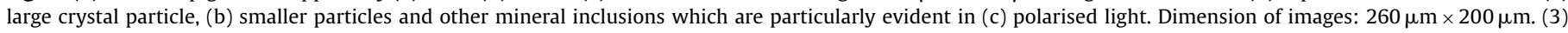
Afghan Lapis Lazuli in plane (a) and plane polarised (b) light. Dimension of images: $260 \mu \mathrm{m} \times 200 \mu \mathrm{m}$.

induced breakdown spectra of lapis lazuli and synthetic ultramarine are immediately apparent, and are here due to the presence of calcium as seen in the loading plot. Importantly, however, LIBS from the stone sample yields different and more widely distributed spectra than those from the pigment samples, likely from the presence of various impurities in the stone sample in comparison to the more homogenous ground pigment samples. Although, the natural pigments contain a large of number of inclusions, as found in optical microscopy, the averaging effect of LIBS on the ground samples is important and visualised in the score plot. Finally, only small differences between the synthetic samples are apparent, and may reflect very slight variations in the materials used for the preparation of the different artificial pigments.

\subsection{Polarized light microscopy}

In order to validate of the results obtained by using pulsed Raman-LIBS measurements, the pigments were investigated using polarized light microscopy for the identification of the particle size of the pigment, the particle size distribution, as well as the presence of other mineral inclusions.

As has been reported by Plesters [1,3], differences between synthetic ultramarine and natural lapis lazuli are reflected in the morphology of particles, in the particle size and in the absence of commonly found minerals which are associated with the extraction of the natural pigment.

As seen in Fig. 6(1), all the synthetic pigments are characterized by very small uniformly sized pigment particles which range from 5 and up to $10 \mu \mathrm{m}$ in diameter, with samples from C.T.S. and Zecchi exhibiting sharper glassy-like particles with relatively well defined edges, ranging in colour from pale to deep blue with increasing size. In contrast, samples from Phase are spherical and uniform in size. In polarized light, only very few isolated birifringent inclusions are evident in samples from Zecchi and C.T.S., suggesting the presence of impurities, and indeed these samples are sufficiently similar in morphology and inclusions that they may come from a common supplier. In contrast, the pigment from Phase is evidently free from inclusions and appears completely dark in polarized light.

In sharp contrast to the synthetic samples, ground lapis lazuli is found with a large concentration of different inclusions, and particles of lazurite with variable particle size and hue. Importantly for the pigments considered, those originating from the Andes exhibit large pigment particles of up to $80 \mu \mathrm{m}$ in length, other smaller sharp crystals of lazurite in varying shades of blue are found which range from 20 to $50 \mu \mathrm{m}$. In addition, as is evident from the photomicrograph in Fig. 6(2), significant inclusions are also found in the samples. In polarized light, the large $(40-50 \mu \mathrm{m})$ bright and birifringent crystals which are ascribed to the large presence of calcite (and other minerals) are particularly evident.

On the other hand, pigment particles from Afghanistan (Fig. 6(3)), are much smaller and darker in colour in comparison with samples from the Andes. In comparison to the synthetic pigment samples, pigment particles, although of similar size $(5-10 \mu \mathrm{m})$ are more variable in shape and are characterized by sharp-edged crystals. Further, and similar to the South American samples, various inclusions (approximately $25 \mu \mathrm{m} \times 25 \mu \mathrm{m}$ ) which are larger than the pigment particles are evident. Small birifringent inclusions are also observed in polarized light, suggesting the presence of calcite within the pigment mixture. 


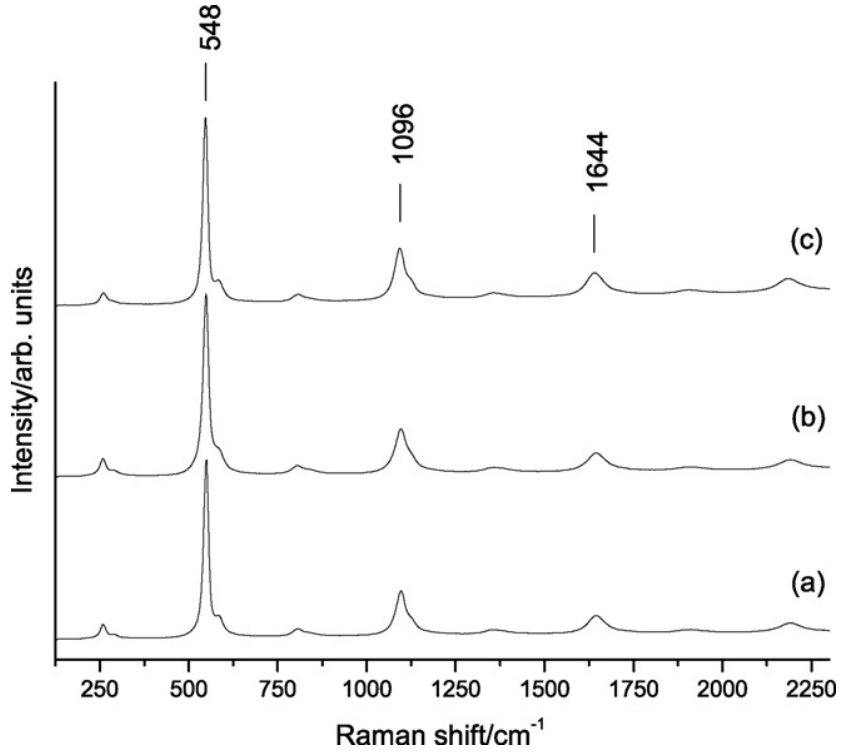

Fig. 7. Micro-Raman spectra of artificial ultramarine blue samples: (a) ART01; (b) ART02; (c) ART03. Bands from calcite are completely absent.

\subsection{Micro-Raman}

Micro-Raman analysis carried out on individual crystals from the pigment samples confirmed the presence of calcite in the natural pigments. Several spectra were acquired on different areas for each pigment samples and are seen in Figs. 7 and 8 . The pigments

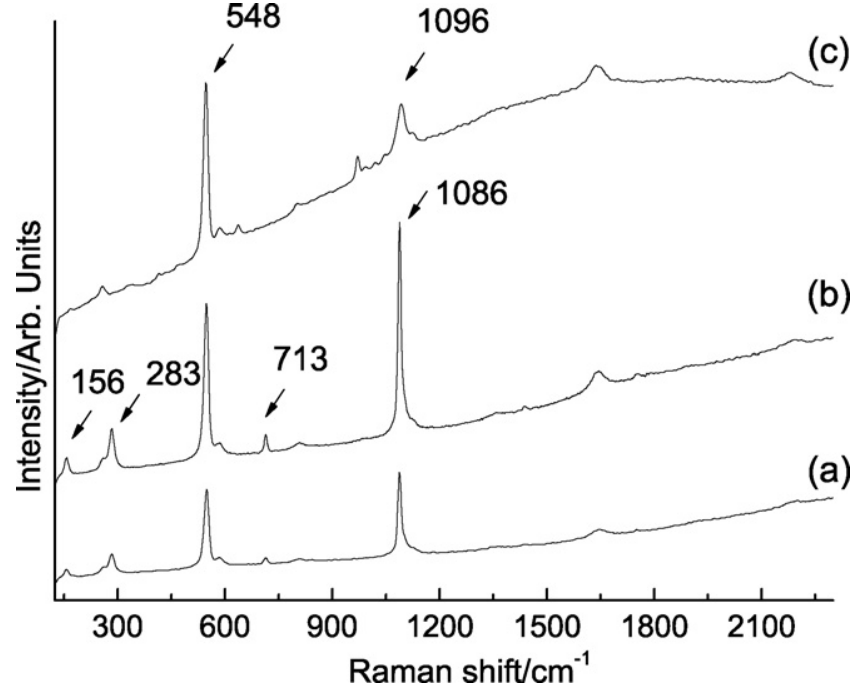

Fig. 8. Micro-Raman spectra of natural ultramarine blue samples: (a) NAT05; (b) NAT04; (c) MIN06. Raman bands from calcite are visible in all the spectra. MicroRaman analysis allows the detection of mineral inclusions found within the pigment Calcite bands are clearly observable at 1086, 713, 283 and $156 \mathrm{~cm}^{-1}$.

and the stone sample show the characteristic Raman bands of lazurite at $258 \mathrm{~cm}^{-1}$, corresponding to the bending vibration $\left(v_{2}\right)$ of the $\mathrm{S}_{3}{ }^{-}$ion, and at $548 \mathrm{~cm}^{-1}$ corresponding to the symmetric stretching vibration $\left(v_{1}\right)$, as found in spectra recorded with pulsed Raman in Fig. 2. The Raman bands corresponding to the overtones of the symmetric stretching of the $\mathrm{S}_{3}{ }^{-}$ion are particularly intense in the

Table 1

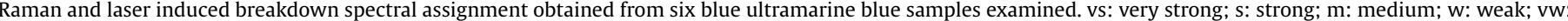
very weak. Numbers in parentheses indicate the intensity of selected peaks.

\begin{tabular}{|c|c|c|c|c|c|}
\hline Sample & $\begin{array}{l}\text { Pulsed Raman, } \\
\text { Raman shift } / \mathrm{cm}^{-1}\end{array}$ & $\begin{array}{l}\text { Micro-Raman, } \\
\text { Raman shift } / \mathrm{cm}^{-1}\end{array}$ & $\begin{array}{l}\text { Raman assignment, mode, } \\
\text { relative intensity }\end{array}$ & $\begin{array}{l}\text { LIBS, wavelength/nm } \\
\text { (intensity/counts) }\end{array}$ & Peak assignment \\
\hline ART01 & 258 & 258 & Lazurite, $\delta\left(\mathrm{S}_{3}{ }^{-}\right), \mathrm{w}$ & 308.2 & $\mathrm{Al}$ \\
\hline ART02 & 548 & 548 & Lazurite, $v_{1}\left(\mathrm{~S}_{3}^{-}\right), \mathrm{s}$ & $309.3(16,000-18,400)$ & $\mathrm{Al}$ \\
\hline \multirow[t]{7}{*}{ ART03 } & 1096 & 1096 & Lazurite, $3 v_{1}\left(\mathrm{~S}_{3}^{-}\right), \mathrm{w}$ & 320.2 & $\mathrm{Ca}$ \\
\hline & & 1644 & Lazurite, $3 v_{1}\left(\mathrm{~S}_{3}^{-}\right), \mathrm{w}$ & 390.5 & $\mathrm{Si}$ \\
\hline & & 2193 & Lazurite, $4 v_{1}\left(\mathrm{~S}_{3}^{-}\right)$, vw & $393.4(6500-15,000)$ & $\mathrm{Ca}$ \\
\hline & & & & $394.4(25,000-30,000)$ & $\mathrm{Al}$ \\
\hline & & & & 396 & $\mathrm{Na}$ \\
\hline & & & & 396.8 & $\mathrm{Ca}$ \\
\hline & & & & 422.7 & $\mathrm{Si}$ \\
\hline NAT04 & & 156 & Calcite, $\mathrm{T}\left(\mathrm{CO}_{3}{ }^{2-}\right), \mathrm{w}$ & 308.2 & $\mathrm{Al}$ \\
\hline \multirow[t]{12}{*}{ NAT05 } & 258 & 258 & Lazurite, $\delta\left(\mathrm{S}_{3}^{-}\right), \mathrm{w}$ & $309.3(10,500-14,500)$ & $\mathrm{Al}$ \\
\hline & & 283 & Calcite, $\mathrm{L}\left(\mathrm{CO}_{3}{ }^{2-}\right), \mathrm{w}$ & $394.4(15,000-17,500)$ & $\mathrm{Al}$ \\
\hline & 548 & 548 & Lazurite, $2 \nu_{1}\left(\mathrm{~S}_{3}^{-}\right), \mathrm{w}$ & 396 & $\mathrm{Al}$ \\
\hline & & 713 & Calcite, $\delta\left(\mathrm{CO}_{3}{ }^{2-}\right), \mathrm{w}$ & 315.9 & $\mathrm{Ca}$ \\
\hline & & 1086 & Calcite, $v_{1}\left(\mathrm{CO}_{3}^{2-}\right)$, vs & $318.1(2000-7500)$ & $\mathrm{Ca}$ \\
\hline & 1096 & 1096 & Lazurite, $2 v_{1}\left(\mathrm{~S}_{3}^{-}\right), \mathrm{w}$ & 330.2 & $\mathrm{Na}$ \\
\hline & & 1644 & Lazurite, $3 v_{1}\left(\mathrm{~S}_{3}^{-}\right), \mathrm{w}$ & 383.5 & $\mathrm{Mg}$ \\
\hline & & 2193 & Lazurite, $4 v_{1}\left(\mathrm{~S}_{3}^{-}\right)$, vw & 384.8 & $\mathrm{Mg}$ \\
\hline & & & & 390.5 & $\mathrm{Si}$ \\
\hline & & & & $393.4(21,500-30,000)$ & $\mathrm{Ca}$ \\
\hline & & & & 396.8 & $\mathrm{Ca}$ \\
\hline & & & & 422.7 & $\mathrm{Ca}$ \\
\hline \multirow[t]{11}{*}{ MIN06 } & 258 & 258 & Lazurite, $v_{1}\left(\mathrm{~S}_{3}^{-}\right), \mathrm{s}$ & 308.2 & $\mathrm{Al}$ \\
\hline & & 548 & Lazurite, $v_{1}\left(\mathrm{~S}_{3}^{-}\right), \mathrm{s}$ & $309.3(15,000)$ & $\mathrm{Al}$ \\
\hline & & 635 & $\begin{array}{l}\text { Wollastonite, } \delta(\mathrm{Si}-\mathrm{O}-\mathrm{Si}) \text {, } \\
\mathrm{w}\end{array}$ & 315.9 & $\mathrm{Ca}$ \\
\hline & 635 & 971 & Wollastonite, $v(\mathrm{Si}-\mathrm{O}), \mathrm{w}$ & $318.1(21,000)$ & $\mathrm{Ca}$ \\
\hline & 971 & 1086 & Calcite, $v_{1}\left(\mathrm{CO}_{3}^{2-}\right)$, vs & 330.2 & $\mathrm{Na}$ \\
\hline & & 1096 & Lazurite, $2 \nu_{1}\left(\mathrm{~S}_{3}^{-}\right), \mathrm{w}$ & 390.5 & $\mathrm{Si}$ \\
\hline & 1096 & 1644 & Lazurite, $3 v_{1}\left(\mathrm{~S}_{3}^{-}\right), \mathrm{w}$ & $393.4(30,000)$ & $\mathrm{Ca}$ \\
\hline & & 2193 & Lazurite, $4 v_{1}\left(\mathrm{~S}_{3}^{-}\right)$, vw & $394.4(15,000)$ & $\mathrm{Al}$ \\
\hline & & & & 396 & $\mathrm{Al}$ \\
\hline & & & & 396.8 & $\mathrm{Ca}$ \\
\hline & & & & 422.7 & $\mathrm{Ca}$ \\
\hline
\end{tabular}


artificial pigments, with vibrations at $1096 \mathrm{~cm}^{-1}\left(2 v_{1}\right), 1644 \mathrm{~cm}^{-1}$ $\left(3 v_{1}\right)$ and $2193 \mathrm{~cm}^{-1}\left(4 v_{1}\right)$, respectively.

The presence of calcite is confirmed in the micro-Raman spectra of natural pigments by the characteristic bands at 1086, 713, 283 and $156 \mathrm{~cm}^{-1}$, corresponding to the symmetric stretching, the in-plane-bending and lattice modes (libration (L) and translation (T)) of the $\mathrm{CO}_{3}{ }^{2-}$ group, respectively [30]. Spectra acquired in different areas of the stone sample have confirmed the presence of the mineral wollastonite $\left(\mathrm{CaSiO}_{3}\right)$ with the bands at 637 and $971 \mathrm{~cm}^{-1}$ as detected in the pulsed Raman spectra which correspond to the $\mathrm{Si}-\mathrm{O}-\mathrm{Si}$ bending vibration and at the $\mathrm{Si}-\mathrm{O}$ stretching vibration as indicated in Table $1[27,31]$.

The differences between the Raman spectra acquired using a pulsed laser source and those using the micro-Raman spectrometer are particularly relevant in the analysis of pigments; here, microRaman effectively allows the analysis of the many different mineral inclusions found within the pigment which is a mixture of different materials. Instead, bulk analysis of an average area of the pressed powdered sample is undertaken with the pulsed-laser setup, hence accounting for the lack of bands ascribed to calcite in the Raman spectrum. On the other hand in LIBS, which is a micro-destructive technique, samples an average cross-section or micro-core of material, but the intense emissions from calcium are evident even in the presence of large concentrations of other elements. Table 1 summarizes the frequencies of molecules vibrations and atomic emissions observed during Raman and LIBS measurements. References to the intensity of some peaks has been given.

\section{Conclusions}

Measurements performed with the combined LIBS and pulsed Raman setup provided complementary information that allowed the characterization of the ultramarine and lapis lazuli pigments. The analysis of blue ultramarine pigments has been performed using a new instrument which yields both molecular and elemental information. Clearly, the trade-off between spatial resolution and the ability to perform elemental analysis with the same instrument is of particular interest for the analysis of large paintings and objects. One drawback of the current setup is that only bulk analysis using both Raman and LIBS can be performed, albeit on a micrometer scale; this may be a problem for the analysis of works of art for which specificity and selectivity are particularly important. Further improvements are expected to allow transportation of the instrument which could allow analysis in situ when there is no possibility for sampling or if there are difficulties in gaining access to a particular object.

Using this instrumentation, the analysis and discrimination of artificial and natural ultramarine blue pigments on the basis of the content of the mineral calcite (and to a lesser extent wollastonite) has been possible. Raman spectra were acquired in ambient or natural light which was spectrally removed applying a specific temporal gate and delay. The presence of such minerals in the natural blue pigments has been confirmed performing also micro-Raman spectroscopy measurements by using a commercial apparatus and polarised light microscopy on pigment samples.

The analysis of standard pigments is a distant analogy to real samples, and it is expected that in situ applications of the methods described for the discrimination of ultramarine samples may be more complex. Weathering agents, pollution or other sources of calcium contamination are anticipated to compromise the detection of calcite inclusions within a pigment mixture. Further, calcium-based materials (lime and gypsum, for example) are often employed for the execution of wall paintings, for the preparation of grounds in paintings and are also found as a pigment.

More generally, within the context of the analysis of painting materials, Raman spectroscopy and LIBS can be used to distinguish the pigments studied and complement microscopic information obtained using polarised light in transmission. Furthermore this study highlights the necessity of a multi-analytical approach when analysing pigments and works of art.

\section{Acknowledgment}

We would like to thank the "Ente Cassa di Risparmio di Firenze" for financial support.

\section{References}

[1] J. Plesters, Ultramarine blue, natural and artificial, in: A. Roy (Ed.), Artists' Pigments, vol. 2, Oxford University Press, New York, 1993, pp. 37-65.

[2] C. Cennini, The Craftsman's Handbook: Translation of Il libro dell'arte, Dover Publications Inc., Mineola, 1960.

[3] J. Plesters, Stud. Conserv. 11 (1966) 62.

[4] S. Bruni, F. Cariati, F. Casadio, L. Toniolo, Vib. Spectrosc. 20 (1999) 15.

[5] D. Ajò, U. Casellato, E. Fiorin, P.A. Vigato, J. Cult. Heritage 5 (2004) 333.

[6] R.J.H. Clark, M.L. Franks, Chem. Phys. Lett. 34 (1975) 69.

[7] M. Bicchieri, M. Nardone, P.A. Russo, A. Sodo, M. Corsi, G. Cristoforetti, V. Palleschi, A. Salvetti, E. Tognoni, Spectrochim. Acta B 56 (2001) 915.

[8] R. Bruder, V. Detalle, C. Coupry, J. Raman Spectrosc. 38 (2007) 909.

[9] P. Vandenabeele, S. Bodé, A. Alonso, L. Moens, Spectrochim. Acta A: Mol. Biomol. Spectrosc. 61 (2005) 2349.

[10] I.M. Bell, R.J.H. Clark, P.J. Gibbs, Spectrochim. Acta 53A (1997) 2159.

[11] G. Burrafato, M. Calabrese, A. Cosentino, A.M. Gueli, S.O. Troja, A. Zuccarello, J. Raman Spectrosc. 35 (2004) 879.

[12] L. Burgio, R.J.H. Clark, Spectrochim. Acta A 57 (2001) 1491.

[13] P. Vandenabeele, T. Weis, E. Grant, L. Moens, Anal. Bioanal. Chem. 379 (2004) 137.

[14] P. Vandenabeele, K. Lambert, S. Matthys, W. Schudel, A. Bergmans, L. Moens, Anal. Bioanal. Chem. 383 (2005) 707.

[15] L. Burgio, K. Melessanaki, M. Doulgeridis, R.J.H. Clark, D. Anglos, Spectrochim. Acta B 56 (2001) 905.

[16] L. Burgio, R.J.H. Clark, T. Stratoudaki, M. Doulgeridis, D. Anglos, Appl. Spectrosc. 54 (2000) 463.

[17] M. Castillejo, M. Martin, D. Silva, T. Stratoudaki, D. Anglos, L. Burgio, R.J.H. Clark, J. Mol. Struct. 550-551 (2000) 191.

[18] A. Giakoumaki, K. Melessanaki, D. Anglos, Anal. Bioanal. Chem. 387 (2007) 749.

[19] A. Brysbaert, K. Melessanaki, D. Anglos, J. Archaeol. Sci. 33 (2006) 1095.

[20] D. Anglos, Appl. Spectrosc. 55 (2001) 186.

[21] E. Tognoni, V. Palleschi, M. Corsi, G. Cristoforetti, Spectrochim. Acta B 57 (2002) 1115.

[22] I. Osticioli, M. Wolf, D. Anglos, Appl. Spectrosc. 62 (2008) 1242.

[23] A. Erdem, A. Çilingiroğlu, A. Giakoumaki, M. Castanys, E. Kartsonaki, C. Fotakis, D. Anglos, J. Archaeol. Sci. 35 (2008) 2486

[24] A.J. López, G. Nicolás, M.P. Mateo, V. Piñón, M.J. Tobar, A. Ramil, Spectrochim. Acta 60 (2005) 1149.

[25] A. Giakoumaki, I. Osticioli, D. Anglos, Appl. Phys. A 83 (2006) 537.

[26] D.U. Tulyaganov, S. Agathopoulos, J.M. Ventura, M.A. Karakassides, O. Fabrichnaya, J.M.F. Ferreira, J. Eur. Ceram. Soc. 26 (2006) 1463.

[27] V. Swamy, L.S. Dubrovinsky, F. Tutti, J. Am. Ceram. Soc. 80 (1997) 2237.

[28] P. Vandenabeele, L. Moens, Analyst 128 (2003) 187.

[29] A. Nevin, I. Osticioli, D. Anglos, A. Burnstock, S. Cather, E. Castellucci, Anal. Chem. 79 (2007) 6143.

[30] F.R. Perez, J. Martinez-Frias, J. Raman Spectrosc. 34 (2003) 367.

[31] S. Gunasekaran, G. Anbalagan, Spectrochim. Acta A 69 (2008) 1246. 